\title{
QUALO SEUDIAGNÓSTICO?
}

Lutero Marques de Oliveira', Lawrence Fabian D. Pupulim², Suzelaine Mesquita², Alessandra Regina da Silva ${ }^{2}$

Trabalho realizado no Hospital Universitário Evangélico de Curitiba, Curitiba, PR. 1. Médico Radiologista do Hospital Universitário Evangélico de Curitiba. 2. Médicos Residentes de Radiologia do Hospital Universitário Evangélico de Curitiba. Endereço para correspondência: Dr. Lutero Marques de Oliveira. Hospital Universitário Evangélico de Curitiba, Departamento de Radiologia. Rua Augusto Stellfeld, 1908. Curitiba, Pr, 80730-150. E-mail: radioSL@bol.com.br

Paciente do sexo feminino, 72 anos de idade, obesa, apresentando-se com dor abdominal súbita, de moderada intensidade, localizada no epigástrio e com piora à palpação. Negava vômitos. Os exames laboratoriais confirmaram discreta icterícia à custa de aumento de bilirrubina direta.

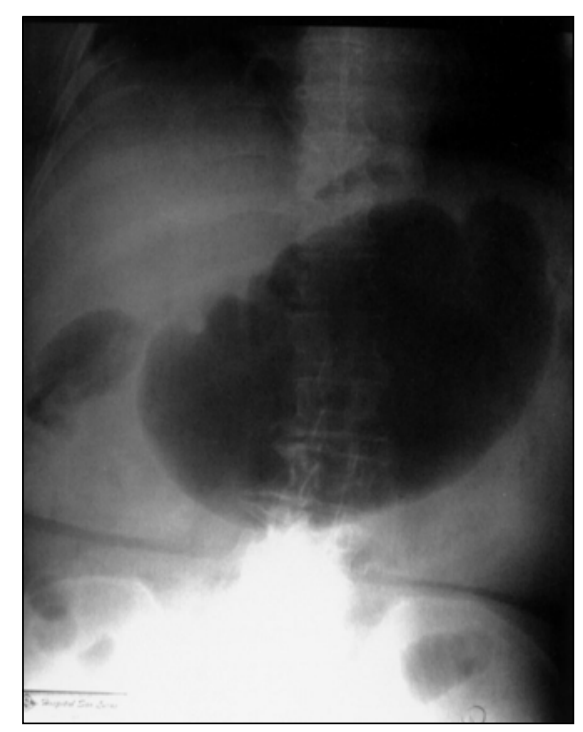

Figura 1. Radiografia simples do abdome.

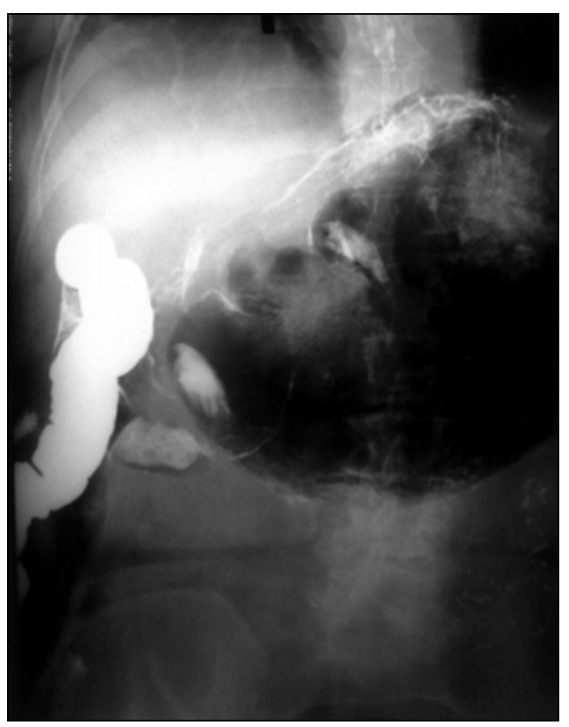

Figura 4. Radiografia de trânsito intestinal com quatro horas.

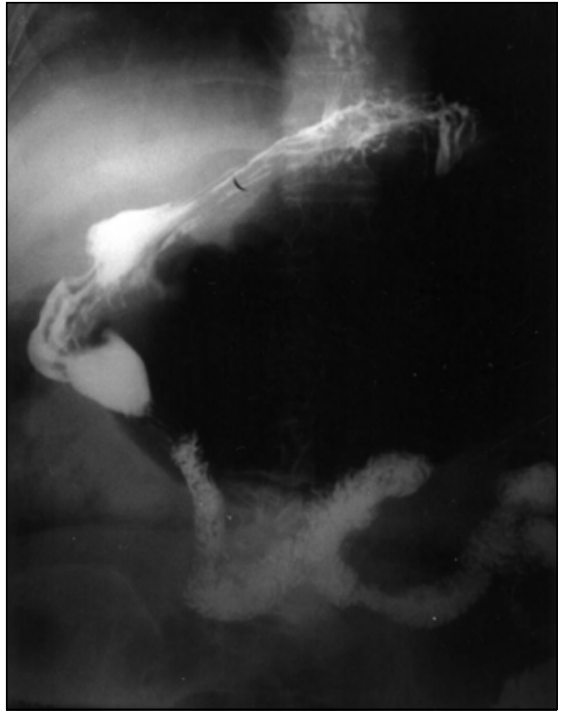

Figura 2. Primeira radiografia do trânsito intestinal.

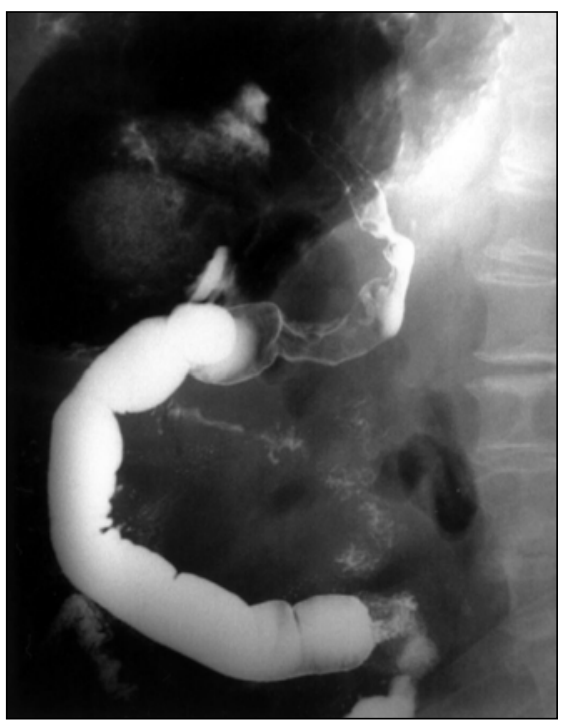

Figura 5. Radiografia de trânsito intestinal com quatro horas, em perfil.

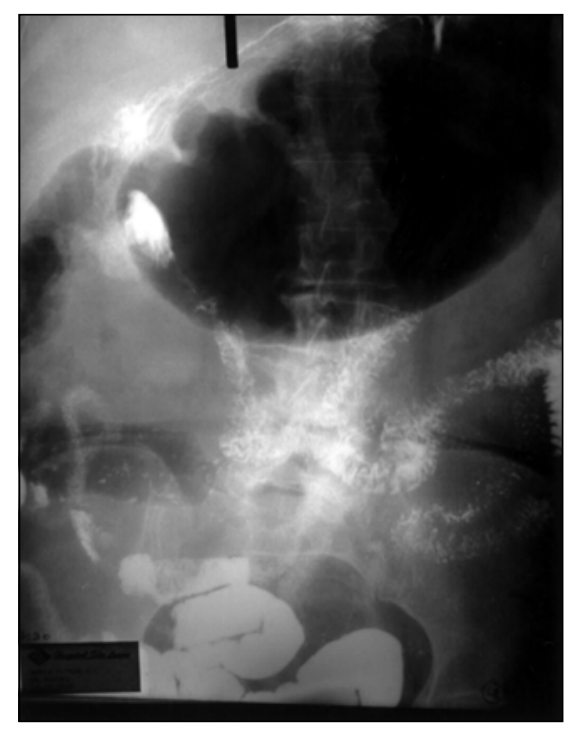

Figura 3. Radiografia de trânsito intestinal uma hora após.

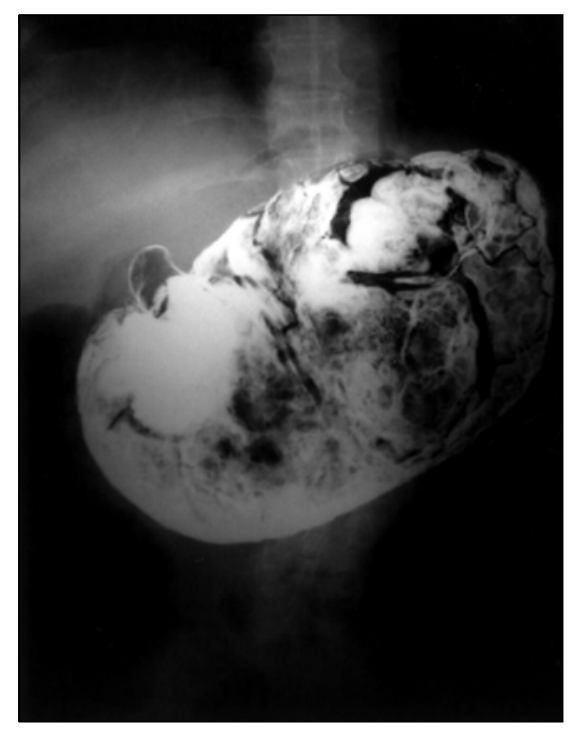

Figura 6. Radiografia de trânsito intestinal realizada no dia seguinte ao início do exame (18 horas após). 


\section{Interpretação dos exames de imagem}

Figura 1. Alça intestinal com importante dilatação localizada na projeção do epigástrio, deslocando superiormente o estômago, que contém pequena quantidade de ar.

Figuras 2 e 3. $O$ contraste no interior do estômago confirma sua localização e seu deslocamento superior. O material de contraste progride pelo duodeno e jejuno.

Figuras 4 e 5. A coluna de contraste progride alcançando alça com aspecto de intestino delgado pouco dilatado, situada à direita do abdome e terminando em área de constrição na região do epigástrio. A alça representa o íleo terminal deslocado superiormente e o local de constrição está na topografia do forame omental (ou forame de Winslow). Observar, na radiografia em perfil, o deslocamento superior e anterior do estômago.

Figura 6. Todo o contraste penetra na alça dilatada e aí se mantém.

Diagnóstico: Hérnia abdominal interna de ceco e cólon ascendente através do forame de Winslow.

\section{COMENTÁRIOS}

Por definição, as hérnias abdominais internas constituem-se em protrusões viscerais através de abertura normal (como no caso do forame de Winslow) ou abertura anormal (congênita ou adquirida) localizada dentro dos limites da cavidade peritoneal ${ }^{(\mathbf{1 , 2})}$. As hérnias internas dividem-se em:

a) paraduodenal: representa a maioria (acima de $50 \%$ ) e pode ser esquerda ou direita;

b) pericecal: representa o segundo tipo mais comum (em torno de 13\%);

c) forame de Winslow: cerca de $8 \%$ das hérnias internas;

d) intersigmóidea;

e) transmesentérica;

f) retroanastomótica.
O forame de Winslow (ou forame omental) estabelece a comunicação entre a cavidade peritoneal maior e a retrocavidade dos epíplons (ou bolsa omental). Seus limites são representados pelo ligamento hepatoduodenal anteriormente, a veia cava posteriormente, o fígado superiormente e o duodeno inferiormente (Figura 7).

Alguns fatores são considerados predisponentes para o desenvolvimento da hérnia através do forame de Winslow, incluindo: forame mais largo que o habitual, mesentério anormalmente longo possibilitando maior mobilidade de alças, ausência de fixação do cólon na parede posterior do abdome, e lobo hepático direito alongado que direciona o deslocamento das alças em direção ao forame de Winslow ${ }^{(2-4)}$.

Os componentes deste tipo de hérnia geralmente são representados por alças de intestino delgado ( $60 \%$ a $70 \%$ das vezes). O ceco e o cólon ascendente são encontrados em aproximadamente $30 \%$ dos casos. Em situações mais raras, o cólon transverso e até a vesícula biliar podem fazer parte da hérnia.

Os sintomas clínicos variam dentro de um amplo espectro, que vai do assintomático ao abdome agudo oclusivo. A dor abdominal está quase sempre presente, tendo intensidade variável entre os casos. É interessante notar que em alguns casos a flexão do tronco pode diminuir a dor, pois esta posição tende a aumentar o diâmetro do forame omental.

A icterícia obstrutiva pode surgir, dependendo do grau de estiramento do ligamento hepatoduodenal ${ }^{(2)}$.

O diagnóstico radiográfico deve-se basear, inicialmente, na localização da imagem aérea patológica ${ }^{(2,3)}$. Uma vez estabelecido que o gás anormal situa-se na retrocavidade dos epíplons, o diagnóstico diferencial deve ser realizado entre três afecções: abscesso, úlcera perfurada e hérnia. No caso da hérnia interna, se a alça não se

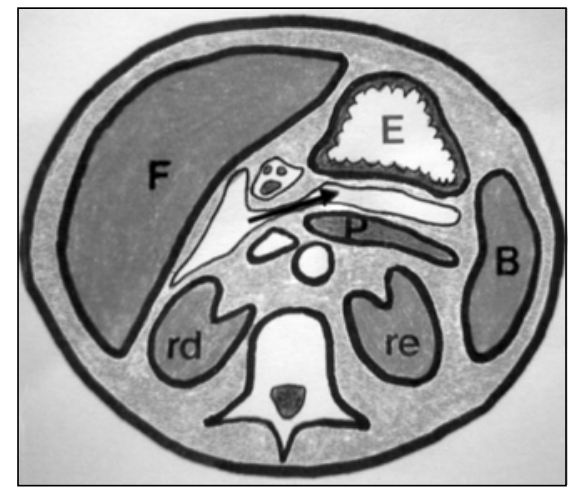

Figura 7. Desenho esquemático de corte axial do abdome na topografia do forame de Winslow (seta), localizado entre a veia cava e o ligamento hepatoduodenal. Observar, ainda, que o forame de Winslow estabelece a comunicação do recesso subhepático da cavidade peritoneal maior com a retrocavidade dos epíplons. Esta última se situa entre o estômago (E) e o pâncreas (P). F, fígado; B, baço; rd, rim direito; re, rim esquerdo.

apresentar tão dilatada e for possível identificar pregas intestinais, o diagnóstico pode ser feito prontamente com a radiografia simples. Em casos duvidosos, oligossintomáticos e sem queixas de abdome oclusivo, o exame contrastado de trânsito intestinal pode ser indicado e é confirmatório, pois:

- reafirma a imagem do estômago e estabelece seu posicionamento;

- identifica a alça intestinal com estreitamento na topografia do forame de Winslow;

- mostra a progressão da coluna de contraste para dentro da alça intestinal herniada.

\section{REFERÊNCIAS}

1. Evrard V, Vielle G, Buyck A, Merchez M. Herniation through the foramen of Winslow. Report of two cases. Dis Colon Rectum 1996;39:1055-7.

2. Meyers M. Radiologia dinâmica do abdome. $4^{\mathrm{a}}$ ed. Rio de Janeiro: Revinter, 1999:505-35.

3. Tran TL, Pitt PC. Hernia through the foramen of Winslow. A report of two cases with emphasis on plain film interpretation. Clin Radiol 1989;40:264 6.

4. Chung CC, Leung KL, Lau WY, Li AK. Spontaneous internal herniation through the foramen of Winslow: a case report. Can J Surg 1997;40:64-5. 